\title{
Impact of minimum wage on gender wage gaps in urban China
}

\author{
Shi $\mathrm{Li}^{1}$ and Xinxin $\mathrm{Ma}^{2^{*}}$
}

\author{
* Correspondence: \\ maxx@ier.hit-u.ac.jp \\ ${ }^{2}$ Institute of Economic Research, 2-1 \\ Naka, Kunitachi-shi, Tokyo 186-8603, \\ Japan \\ Full list of author information is \\ available at the end of the article
}

\begin{abstract}
This paper provides evidence on whether the minimum wage (MW) has affected gender wage gaps in urban China. Several major conclusions emerge. First, from 1995 to 2007, the proportion of workers whose wages were below the regional MW level was greater for female workers than for male workers. Second, the results obtained by using the difference-in-differences estimation method show that from a long-term perspective, the MW will help to reduce gender wage gaps and that the effect is more obvious for the low-wage group. However, in the short term, the amelioration effect is not obvious.

JEL classification: J31, J48, J71

Keywords: The minimum wage, Gender wage gap, Urban China
\end{abstract}

\section{Introduction}

Does the minimum wage (MW) policy that has been enforced since 1993 affect gender wage differentials in China? In this paper, we provide evidence on this issue. We focus on the effect of MW policy on the gender wage gaps ${ }^{1}$ for the following two reasons.

First, the implementation of the MW, in theory, may increase the income of lowwage workers and is beneficial to reduce poverty. Therefore, the MW is enacted as an important labor policy. To examine the policy effect, many empirical analyses have been conducted in other countries. In contrast, although the MW has been in effect since 1993 in China, empirical analysis of it using micro-data is rare.

Second, while the main objective of MW implementation is to increase the wage level of low-wage groups, most studies only focus on the effect of MW on low-skill worker employment ${ }^{2}$ (which appears to be the most important issue). Moreover, these studies overlook the effect of MW on wage gaps, particularly gender wage gaps. The effects of the MW on gender wage gap depend on many factors. Some of these factors include, the gender gap in the proportion of workers whose wages are below the regional MW level and the gender gap between actual wages and the MW level before the implementation of the MW (Robinson 2002, 2005). Therefore, although the implementation of the MW does not imply a reduction of gender wage gap in theory, we need to verify its effects through an empirical analysis.

This paper attempts to answer the following questions through an empirical analysis using micro-data from Chinese Household Income Project (CHIP) survey. First, is the proportion of the population with wages below the MW level greater for males than 
for females? Is the gap between actual wages and the MW level greater for females than for males? Second, would different MW levels adopted in various regions lead to a regional difference in gender wage gap? Third, does the MW system affect gender wage gap? What are the effects of endowment differentials? What are the effects of endowment return differentials? Fourth, has the MW system, which was implemented in 1993, affected the gender wage gap? If it has, is there a difference in short-term and long-term effects? Because we use the cross-sectional micro survey data from three periods, a repeated cross-section analysis should also investigate the changes (if any) in the abovementioned issues along with policy changes. Considering that the MW primarily affects low-income groups, we employ different models to conduct the analysis on average wages and wage distribution.

This paper is structured as follows. Part II introduce the implementation of the MW in China, Part III reviews the literature. Part IV describes analysis methods, including introduction to data and models. Part $\mathrm{V}$ answer the first question presented above using statistical description results. Part VI states the quantitative analysis results to answer the second, third and fourth questions. Part VII presents the main conclusions.

\section{The implementation of the MW in China}

In China, since the 1980s, there has been increasing migration from rural to urban areas, which has been accompanied by an increase in the low wages of migrants and a rise in income inequality. To deal with these social problems, the MW policy was first promulgated as a law in 1993. The MW is applicable to two kinds of wages, the monthly wage and the hourly wage. Minimum monthly wage standards are applied to regular workers, while the minimum hourly wage is applied to non-regular workers. Wage, which is defined by the MW policy, is the basic wage with the exception of overtime work payment and some allowances.

As per policy, the MW level is determined by the regional government, the union, and the representatives of companies. However, in reality, MW levels are determined primarily by the regional governments.

The MW level is adjusted once every two years, according to many factors such as the regional lowest living cost, consumer price index of urban residents, social insurance, the housing fund that individual workers are paid, the regional average wage level, the status of economic development, and employment status. The adjustment of the MW level is carried out by the local government (province or city governments); as a result, there are regional disparities. For example, the MW level is higher in the eastern regions as compared to the western and central regions, and the increase within these bands of the MW levels are also different across regions (see Fig. 1). These regional disparities allow us to use a quasi-natural experiment model to prove the effects of MW. We will provide detailed explanations about this in the following paragraphs.

Although the government enforced the implementation of the MW, there are no penalties for violations; hence, there are several compliance problems and MW is not thoroughly implemented in the private sector. These compliance problems account for the phenomenon of workers with wages below the prescribed level, although the MW has been in existence since 1993. 


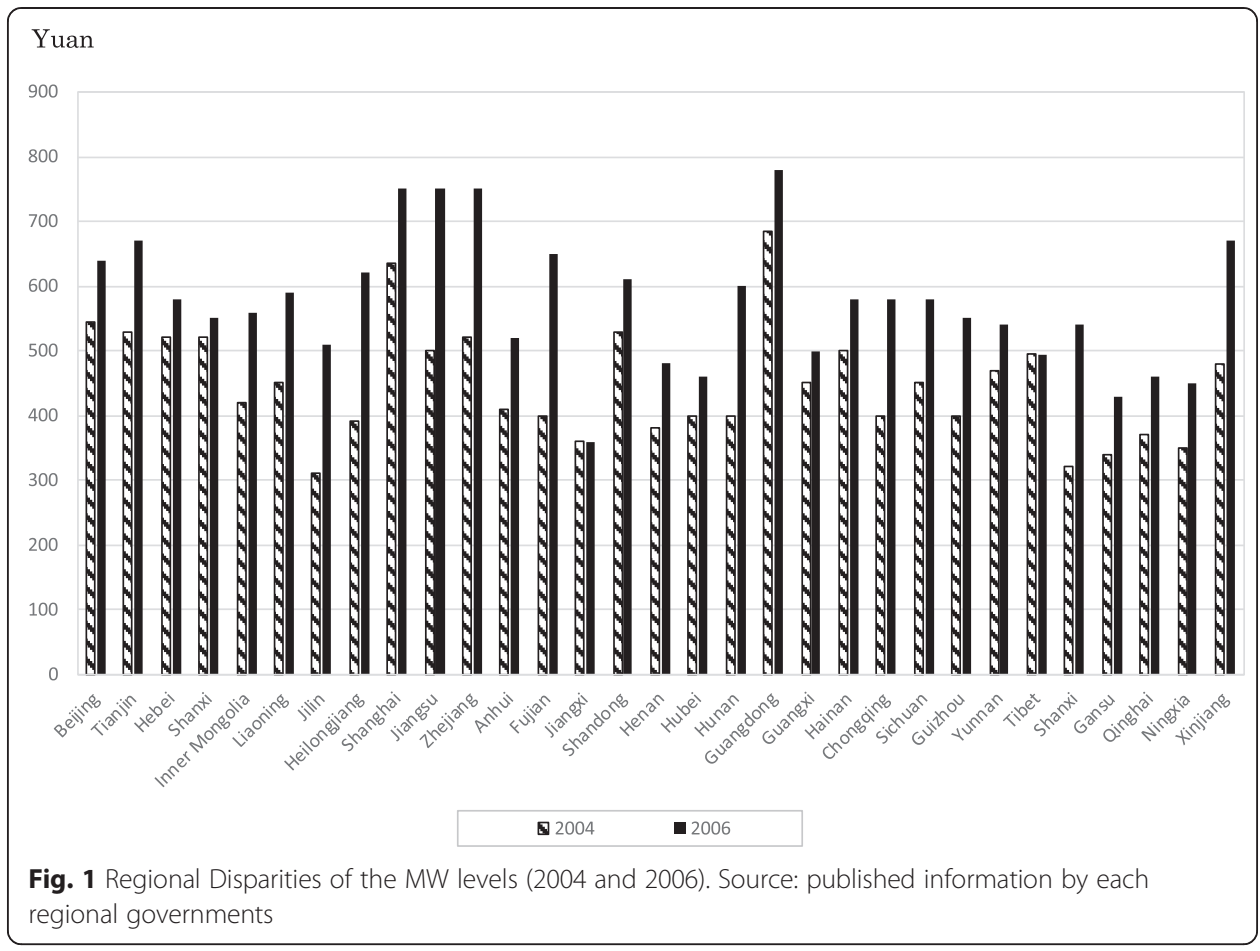

\section{Literature review}

There are a large number of empirical studies of the effects of the MW on employment, but the studies on wage distribution are scarce. The studies related to the empirical analyses in this paper are reviewed in the following.

DiNardo et al. (1996) conducted studies on the effects of a MW on a wage gap. In particular, they assumed other things equal to evaluate the wage distribution in 1988 based on the fixed MW level in 1979, and then compared the 1979 level with the actual level in 1988 to reveal the effects of the MW system on a wage gap. The analysis shows that there is an increase in the wage gap in 1988 compared with 1979; the decrease of the MW level results in an increased wage gap (17\% for male, $24 \%$ for female). Card and Krueger (1995) conducted a study on the effects of changes in the MW level from 1989 to 1992 on changes in wage gaps in the U.S. Using a natural experiment model based on the MW system change, in which the MW level was increased in some states in 1990 and 1991, they indicated that the Minimum Wage Act pulled up the incomes of low-wage workers and narrowed the regional wage gap.

In addition, to investigate the effects of the MW on gender wage gap, Robinson (2002, 2005) uses the British Labor Force Survey data from 1997 to 2000 to study the effects of the MW implemented throughout the country in April 1999 on gender wage gap. The analysis, based on a quasi-DID model (using London, whose gender wage gap is the smallest before the implementation of the MW, as a control group and other regions as treatment groups), shows that the effects of the MW on gender wage gap vary in different regions. Shannon (1996) utilized the Canadian Labor Force Survey data in 1986 and the Oaxaca-Blinder decomposition method to conduct a relevant study that shows that the MW narrowed the gender wage gap among the population aged 16 to 24 but had little effect on those aged 25 to 64 . 
Currently, there is no empirical analysis of the effects of the MW on gender wage gap in urban China. Our study may address this lack to a certain extent.

\section{Methodology and data}

\subsection{Model}

\section{(1) Robinson model for the effects of the MW on gender wage gap}

Robinson $(2002,2005)$ established a model to analyze the effects of the MW system on gender wage gap in the UK. This model is primarily used to show that there are two reasons for the effects of the MW on gender wage gap. First, the MW level (MW) has various effects on wage distribution:

$$
\begin{gathered}
W_{i}=W_{i} \quad \text { if } \quad W_{i}>M W \\
W_{i}=M W \quad \text { if } \quad W_{i}^{*} \leq M W
\end{gathered}
$$

Equation (1) shows that for groups with a wage greater than the MW level $\left(W_{i}>M W\right)$ before the implementation of the MW, the wage remains the same after such implementation; whereas, for those with a wage lower than the MW level $\left(W_{i}^{*} \leq M W\right)$ before the implementation, the wage increases to the MW level after such implementation. As a result, the average wage after the implementation of the MW should be a composite value affected by these two weights and expressed as follows:

$$
\begin{aligned}
\ln \bar{W}_{\text {after }} & =\left[\sum_{m w} \frac{(M W)}{N_{m w}}\right] *\left(\frac{N_{m w}}{N}\right)+\left[\sum_{N-N_{m w}} \frac{\left(W_{i}\right)}{N-N_{m w}}\right]\left(\frac{N-N_{m w}}{N}\right) \\
& =\sum_{m w}(M W) * \frac{1}{N}+\sum_{N-N_{m w}}\left(W_{i}\right) * \frac{1}{N}
\end{aligned}
$$

The changes in the average wage before and after such implementation can be expressed as follows:

$$
\Delta \bar{W}=\frac{1}{N}\left[\sum_{m w}\left(M W-W_{i}\right)\right]
$$

Equation (3) indicates that there are two reasons for the changes in average wage before and after the implementation of the MW: the number of workers with wages lower than the MW level and the gap between the actual wage and the MW level. Consequently, the gender wage gap before the implementation of the MW can be expressed as Eqs. (4) and (5):

$$
\begin{aligned}
& \left(\frac{\bar{W}_{f}}{\bar{W}_{m}}\right)^{\text {before }}=\frac{\sum_{W_{f} \leq M W}\left(W_{f}\right) * 1 / N_{f}+\sum_{W_{m} \leq M W}\left(W_{m}\right) * 1 / N_{m}+\sum_{W_{m}>M W}\left(W_{m}\right) * 1 / N_{m}}{\sum_{\left(\frac{W_{f}}{W_{m}}\right)^{a f t e r}}=} \\
& \sum_{W_{f} \leq M W}(M W) * 1 / N_{f}+\sum_{W_{f}>M W}\left(W_{f}\right) * 1 / N_{f}
\end{aligned}
$$


The following assumptions are drawn based on a comparison between Eqs. (4) and (5). i. When the number of females is greater than that of males among workers having wages lower than the MW level before the implementation of the MW, and ii. When the gap between actual wages and the MW level for females is greater than that for males before the implementation of the MW, such an implementation may contribute to narrowing the gender wage gap at the low-wage distribution.

Because i. and ii. stated above are only assumptions, the implementation of the MW does not imply a certain reduction of gender wage gap in theory. Further investigations must be conducted with the following models.

\section{(2)Estimates of gender wage gap of regions by the MW level}

Based on the MW level, we classified the samples into high MW regions, medium MW regions and low MW regions ${ }^{3}$ to estimate the wage function. The wage function is represented with Eq. (6).

$$
\ln W_{i j t}=a_{i j t}+\beta X_{i j t}+\varepsilon_{i j t}
$$

In Eq. (6), $i$ represents individual workers, $t$ represents periods and $j$ represents three categories of regions (high MW regions, middle WM regions and low MW regions). $X$ is other variables affecting wages (such as education and work experience as a proxy for human capital, or male dummy variable), $a$ is a constant, $\varepsilon$ is an error term and $\beta$ represents the coefficient estimates of variables. Using coefficients of the male dummy estimated by regional sub-groups, we compare the regional differentials of gender wage gaps. ${ }^{4}$

To see the different effects by wage distribution, we adopt the Quantile Regression Model (Koenker and Baset 1978), which can be expressed as:

$$
\min _{X(\theta)}\left[\sum_{h: \ln W_{i} \geq \beta(\theta) X_{i}} \theta\left|\ln W_{i}-\beta(\theta) X_{i}\right|+\sum_{\substack{\left.h: \ln W_{i}<\beta \theta\right) X_{i} \\ \rho_{\theta} \in(0,1)}}(1-\theta)\left|\ln W_{i}-\beta(\theta) X_{i}\right|\right]
$$

In Eq. (7), $i$ represents individual workers, and $\theta$ represents quantile of wages (1\% quantile is expressed as 1th). The equation's other variables are the same as those of Eq. (6). $\rho_{\theta}$ (.) is a check (or indicator) function. The QR model is designed for estimation using the optimal method, which minimizes the two error terms in Eq. (7).

(3)Decomposition model for the effects of the MW level on gender wage gaps

To decompose the effect on gender wage gaps, the Oaxaca-Blinder decomposition method $^{5}$ (Oaxaca 1973; Blinder 1973) is commonly used. However, Cotton (1988); Neumark (1988) and Oaxaca and Ransom (1994) note that the Oaxaca-Blinder decomposition method using estimated coefficient and average values of males or females 
may lead to an index number problem. To address this problem, this paper adopts the Oaxaca-Ransom decomposition model (Oaxaca and Ransom 1994).

$$
\ln \bar{W}_{m}-1 \mathrm{n} \bar{W}_{f}=\left(\bar{X}_{m}-\bar{X}_{f}\right) \beta^{*}+\bar{X}_{f}\left(\beta^{*}-\beta_{f}\right)+\bar{X}_{m}\left(\beta_{m}-\beta^{*}\right)
$$

In Eq. (8), $m$ represents males, $f$ represents females, $\ln \bar{W}$ is the logarithm of the average wage, $\bar{X}$ is the average of variables, and $\beta_{m}$ and $\beta_{f}$ represent the estimated coefficients resulting from the wage function of males and females, respectively. Note the $\beta^{\text {* }}$ (no-discrimination wage structure) therein, which is a gender-neutral coefficient estimated based on wage functions using the entire sample. Concerning the Oaxaca and Ransom model, $\left(\bar{X}_{m}-\bar{X}_{f}\right) \beta^{*}$ represents the gender wage gap resulting from a difference in endowment including, for example, human capital, $\bar{X}_{f}\left(\beta^{*}-\beta_{f}\right)$ represents the gap caused by too-low endowment return of females (known as "female loss") and $\bar{X}_{m}\left(\beta_{m}-\beta^{*}\right)$ represents the gap generated by too-high endowment return of males (known as "male gain"). The sum of these two decomposition values stands for the gender wage gap resulting from differences in endowment return, including discrimination. ${ }^{6}$ We add the variable of the MW levels and Kaitz Index ${ }^{7}$ in this model to decompose these MW factors' effects on gender wage gap.

\section{(4)DID analysis for the effects of the MW on gender wage gap}

Although the effect of the MW on gender wage gap can be decomposed by the endowment difference and endowment returns difference as described above, it is necessary to provide evidence on whether the MW has affected gender wage differentials. Here, we apply the DID model, which is frequently used for policy evaluation. DID analysis ${ }^{8}$ can be represented as follows:

$$
\begin{aligned}
\ln W_{i j t}=a & +\gamma_{x} X_{i j t}+\gamma_{y e} \text { Year }_{i j}+\gamma_{t r} \text { Treat }_{i j t}+\gamma_{m} \text { Male }_{i j t}+\gamma_{\text {yetr }} \text { Year }^{*} \text { Treat }_{i j t} \\
& +\gamma_{\text {yem }} \text { Year } * \text { Male }_{i j t}+\gamma_{\text {trm }} \text { Treat } * \text { Male }_{i j t}+\gamma_{\text {did }} \text { DID }_{i j t}+v_{i j t}
\end{aligned}
$$

In Eq. (9), $i$ stands for the individual, $t$ for years, $j$ represents categories of regions, Year for policy implementation years (1995, 2002 and 2007 in this paper), Treat for the treatment group, Male for the male dummy variable, $a$ is the constant term, and $v$ is the error term. $\gamma$ represents the estimated coefficient for each variable.

We used the retrospective data of CHIP1995 to gain wages information for the previous five years and generated several treatment groups and control groups. ${ }^{9}$ Specifically, we use the years before the implementation of the MW (1990, 1991, 1992, 1993, and 1994) as the initial years and the years of 1995, 2002 and 2007 as the policy implantation years. We distinguish the treatment group and control group.

We sampled districts with relatively large gender wage gaps in the initial years before the implementation of the MW and relatively high MW levels (where the value of Kaitz index is higher) during the implementation years as the simulation treatment groups. It is thought that the MW should provide the largest effect to this group. For example, using the 1990-1995 data, we defined Henan province as a treatment group because the gender wage gap is largest in 1990, as the ratio of female and male wage is 0.78 , while in other districts it is $0.80 \sim 0.86$; accordingly, the Kaitz index is highest 
(Henan is 0.44 , the other districts are $0.25 \sim 0.38$ ). On the other hand, we sampled districts with relatively small gender wage gaps during the initial years and a MW level lower than that of the treatment group in the policy implementation years as a control group. In this case, the MW should have the smallest effect on these groups. Since 1993, MW was implemented across all districts in China; therefore, we cannot treat a non-implementation district as a treatment group (this is the strict definition). Accordingly, we defined the treatment groups as the district most impacted by the MW implementation. ${ }^{10}$

Here, the DID item is the cross term of the three items used-male, the policy implementation years and treatment group (Male* Year*Treat). If the estimated coefficient of DID is statistically significant, it indicates that the implementation of the MW has an effect on gender wage gap. If the estimated coefficient is a negative value, it shows that the MW system has some effect on reducing gender wage gap, and vice versa.

\subsection{Data}

CHIP1995, 2002, 2007 are used for the analysis. These data are gained from the three surveys of the CHIP conducted by NBS, Economic Institute of CASS and Beijing Normal University, including respective information about employment and wages of urban residents. Using retrospective survey data of income in CHIP1995, we can differentiate the years before and after the MW implementation to analyze the treatment group and control group.

Because there are design similarities of the data in the questionnaire, we can use the same information for analysis for all three periods. To make comparisons in three periods, we selected the regions (provinces) covered in all three surveys, including Beijing, Shanxi, Liaoning, Jiangsu, Anhui, Guangdong, Henan, Hubei, Sichuan, Yunnan, and Gansu. ${ }^{11}$

The wage ${ }^{12}$ is defined as the total earnings from work (called "the total wage"). Here, it comprises the basic wage, bonus, cash subsidy, and no cash subsidy. ${ }^{13}$ We use the CPI in 1995 as the standard, and adjust the nominal wage in 2002 and 2007.

The analytic objects of this paper are employees, excluding the self-employer and the unemployed. Considering the retirement system of the state-owned sector, to reduce the effect of that system on the analysis result, the analytic objects are limited in the groups to between the ages of 16 and 60 .

In the wage function, the explained variable is the logarithm of the monthly wage, ${ }^{14}$ and the explaining variables are the variables likely to affect the wage, such as education (primary school or below, junior high school, senior high school/vocational school, college, university ${ }^{15}$ and above), experience years, ${ }^{16}$ ownership (state-owned enterprises, collectively owned enterprises, foreign/private enterprises), occupation (manager, technician, clerk, manual worker), industry (agriculture, fishing \& forestry, manufacturing, mining, construction, transportation/communication, wholesale, retail, and catering, real estate, health and social welfare, education, culture, and arts, financial industry, public management and social organizations, and other industries).

We apply the Chinese National Minimum Wage Databases to classify the regions by the MW level, as shown in Table 1. Table 2 shows sample statistical descriptions by gender groups. 
Table 1 Regional classification by the MW levels

\begin{tabular}{lllll}
\hline & & Low-MW region & Mid-MW region & High-MW region \\
\hline 1995年 & level & 160-165 Yuan & 165-175 Yuan & over 175 Yuan \\
& regions & $\begin{array}{l}\text { Shanxi, Anhui, Shichuan, } \\
\text { Yunnan, Gansu }\end{array}$ & Jiangsu, Hernan, Hubei & Beijing, Liaoning \\
2002年 & level & 225-285 Yuan & 285-330 Yuan & over 330 Yuan \\
& regions & Shanxi, Hernan, Shichuan, & Liaonin, Anhui, Hubei, & Beijing, Jiangsu, \\
& Gansu & Yunnan & Guangdong \\
2007年 & level & 375-510 Yuan & 510-615Yuan & over 615 Yuan \\
& regions & Anhui, Hubei, Yunnan, Gansu & Shanxi, Liaonin, Hernan, & Beijing, Jiangsu \\
& & & Guangdong, Shicuan & \\
\hline
\end{tabular}

Note: Chinese National Minimum Wage Database

\section{Descriptive statistics results}

5.1 Proportions of male and female with wages below the MW level

The gender gaps of proportions of workers with wages below the MW level are shown in Fig. 2. The proportion of workers with wages below the MW level all are greater for females than for males in 1995 (3.2 percentage points), 2002 (1.4 percentage points) and 2007 (2.1 percentage points).

\subsection{The gender gap of the difference between wage and the MW level}

We subtracted the MW level from the wage as an index to show how serious the gap is between the wage and the MW level. A greater numerical value is associated with a larger gap between the wage and the MW level, i.e., the more serious is the amount by which the wage is lower than the MW level. We provide the results calculated by year, gender and groups in Fig. 3.

In 1995, the gender gap between the wage and the MW level was 8.0 yuan. In 2002 and 2007, however, the gaps between male and female are -8.9 yuan (2002) and -22.1 yuan (2007), respectively. These calculations show that in 1995, females' wages were considerably lower than the MW level compared with those of males; in 2002 and 2007, in contrast, males' wages were considerably lower than the MW level compared with those of females.

\section{Econometric analysis results}

\subsection{Estimated results of gender wage gaps in regions with different MW}

Table 3 shows the estimated gender wage gaps by the regional groups. We observe gender wage gaps in all regions through the estimated coefficient of male dummy.

First, the gender wage gap is the greatest in the high MW region; the coefficient is 0.1454 , which is followed by the low MW region with an estimated coefficient of 0.1239. In the middle MW region, the gender wage gap is smallest, with an estimated coefficient of 0.0762 .

Second, the main results using the QR model are as follows. (1) Whether in the high MW region, middle MW region or low MW region, in the lowest-wage groups (e.g., 1st quantile), the estimated coefficients of the male dummy variable are not statistically significant, which indicates that the gender wage gap is rather small in the low-wage distribution. Conversely, in all regional groups whose wage distributions are greater over the 6th quantile, the male dummy coefficients are statistically significant at $1 \%$ or 
Table 2 Statistical descriptions

\begin{tabular}{|c|c|c|c|c|c|c|c|c|c|}
\hline & \multicolumn{3}{|l|}{1995} & \multicolumn{3}{|l|}{2002} & \multicolumn{3}{|l|}{2007} \\
\hline & Male & Female & F-M & Male & Female & F-M & Male & Female & F-M \\
\hline Monthly wage & 536 & 462 & $86.2 \%$ & 1045 & 852 & $81.5 \%$ & 1722 & 1271 & $73.8 \%$ \\
\hline \multicolumn{10}{|l|}{ Education } \\
\hline Elementary school or less & $3.6 \%$ & $5.6 \%$ & $1.9 \%$ & $2.2 \%$ & $2.5 \%$ & $0.4 \%$ & $2.2 \%$ & $2.2 \%$ & $0.0 \%$ \\
\hline Junior high school & $28.1 \%$ & $32.7 \%$ & $4.6 \%$ & $24.3 \%$ & $21.7 \%$ & $-2.7 \%$ & $20.4 \%$ & $17.0 \%$ & $-3.4 \%$ \\
\hline Senior high school & $38.9 \%$ & $44.2 \%$ & $5.3 \%$ & $37.7 \%$ & $45.1 \%$ & $7.4 \%$ & $35.3 \%$ & $40.4 \%$ & $5.1 \%$ \\
\hline College & $18.7 \%$ & $12.5 \%$ & $-6.2 \%$ & $23.0 \%$ & $23.0 \%$ & $0.0 \%$ & $24.5 \%$ & $27.7 \%$ & $3.2 \%$ \\
\hline University & $10.7 \%$ & $5.1 \%$ & $-5.6 \%$ & $12.8 \%$ & $7.7 \%$ & $-5.1 \%$ & $17.6 \%$ & $12.7 \%$ & $-5.0 \%$ \\
\hline Years of experience & 28 & 27 & -2 & 30 & 27 & -3 & 31 & 28 & -3 \\
\hline Han & $95.4 \%$ & $95.3 \%$ & 0.0 & $96.0 \%$ & $95.9 \%$ & $-0.1 \%$ & $97.4 \%$ & $96.9 \%$ & $-0.5 \%$ \\
\hline Married & $87.1 \%$ & $87.9 \%$ & $0.8 \%$ & $89.1 \%$ & $86.6 \%$ & $-2.5 \%$ & $88.4 \%$ & $86.4 \%$ & $-2.0 \%$ \\
\hline \multicolumn{10}{|l|}{ Ownership } \\
\hline SOE & $86.2 \%$ & $76.9 \%$ & $-9.3 \%$ & $70.0 \%$ & $64.5 \%$ & $-5.5 \%$ & $59.4 \%$ & $49.7 \%$ & $-9.7 \%$ \\
\hline COE & $12.0 \%$ & $20.7 \%$ & $8.7 \%$ & $5.5 \%$ & $9.0 \%$ & $3.5 \%$ & $5.1 \%$ & $7.0 \%$ & $1.9 \%$ \\
\hline Foreign/Private Firm & $1.5 \%$ & $1.7 \%$ & $0.2 \%$ & $23.4 \%$ & $23.9 \%$ & $0.5 \%$ & $29.3 \%$ & $30.3 \%$ & $1.0 \%$ \\
\hline Others & $0.2 \%$ & $0.7 \%$ & $0.5 \%$ & $1.2 \%$ & $2.6 \%$ & $1.4 \%$ & $6.2 \%$ & $13.1 \%$ & $6.8 \%$ \\
\hline \multicolumn{10}{|l|}{ Occupation } \\
\hline Manager & $17.3 \%$ & $6.3 \%$ & $-11.0 \%$ & $19.8 \%$ & $9.3 \%$ & $-10.5 \%$ & $6.7 \%$ & $2.8 \%$ & $-4.0 \%$ \\
\hline Engineer & $19.5 \%$ & $22.2 \%$ & $2.6 \%$ & $17.8 \%$ & $23.8 \%$ & $6.0 \%$ & $33.3 \%$ & $37.5 \%$ & $4.2 \%$ \\
\hline Clerical staff & $22.5 \%$ & $23.4 \%$ & $0.9 \%$ & $20.4 \%$ & $22.8 \%$ & $2.4 \%$ & $20.5 \%$ & $19.1 \%$ & $-1.4 \%$ \\
\hline Manufacturingl worker & $37.7 \%$ & $41.4 \%$ & $3.7 \%$ & $32.6 \%$ & $23.1 \%$ & $-9.4 \%$ & $23.9 \%$ & $11.7 \%$ & $-12.2 \%$ \\
\hline Others & $2.9 \%$ & $6.7 \%$ & $3.8 \%$ & $9.4 \%$ & $21.0 \%$ & $11.5 \%$ & $15.6 \%$ & $28.9 \%$ & $13.3 \%$ \\
\hline \multicolumn{10}{|l|}{ Industry } \\
\hline Agriculture, forestry, fisheries & $2.1 \%$ & $1.3 \%$ & $-0.8 \%$ & $1.3 \%$ & $1.3 \%$ & $0.0 \%$ & $1.0 \%$ & $0.7 \%$ & $-0.3 \%$ \\
\hline Manufacturing & $43.3 \%$ & $41.7 \%$ & $-1.6 \%$ & $26.4 \%$ & $23.3 \%$ & $-3.1 \%$ & $22.5 \%$ & $15.1 \%$ & $-7.4 \%$ \\
\hline Mining & $1.2 \%$ & $0.9 \%$ & $-0.3 \%$ & $2.1 \%$ & $0.8 \%$ & $-1.3 \%$ & $1.5 \%$ & $0.6 \%$ & $-1.0 \%$ \\
\hline Construction & $3.3 \%$ & $2.7 \%$ & $-0.6 \%$ & $4.2 \%$ & $2.2 \%$ & $-2.0 \%$ & $4.1 \%$ & $1.8 \%$ & $-2.3 \%$ \\
\hline Transportation/communication & $5.9 \%$ & $4.3 \%$ & $-1.6 \%$ & $10.2 \%$ & $5.1 \%$ & $-5.1 \%$ & $13.6 \%$ & $6.5 \%$ & $-7.1 \%$ \\
\hline Wholesale,retail and catering & $12.1 \%$ & $17.3 \%$ & $5.2 \%$ & $9.9 \%$ & $15.4 \%$ & $5.5 \%$ & $11.1 \%$ & $18.6 \%$ & $7.5 \%$ \\
\hline Real estate & $3.3 \%$ & $4.0 \%$ & $0.7 \%$ & $6.0 \%$ & $4.4 \%$ & $-1.6 \%$ & $7.7 \%$ & $5.3 \%$ & $-2.4 \%$ \\
\hline Health and Social Welfare & $3.6 \%$ & $5.8 \%$ & $2.3 \%$ & $4.0 \%$ & $6.7 \%$ & $2.7 \%$ & $3.2 \%$ & $5.6 \%$ & $2.4 \%$ \\
\hline Education Arts and Culture & $6.4 \%$ & $8.0 \%$ & $1.6 \%$ & $8.4 \%$ & $9.8 \%$ & $1.3 \%$ & $8.4 \%$ & $10.8 \%$ & $2.4 \%$ \\
\hline Technical Services & $2.7 \%$ & $2.1 \%$ & $-0.6 \%$ & $9.3 \%$ & $15.6 \%$ & $6.4 \%$ & $2.6 \%$ & $1.6 \%$ & $-1.0 \%$ \\
\hline Financial Industry & $1.8 \%$ & $2.1 \%$ & $0.3 \%$ & $2.4 \%$ & $3.0 \%$ & $0.6 \%$ & $2.9 \%$ & $4.0 \%$ & $1.1 \%$ \\
\hline $\begin{array}{l}\text { Public administration and social } \\
\text { organizations }\end{array}$ & $13.6 \%$ & $9.1 \%$ & $-4.5 \%$ & $13.6 \%$ & $10.2 \%$ & $-3.4 \%$ & $15.1 \%$ & $15.9 \%$ & $0.8 \%$ \\
\hline Others & $0.7 \%$ & $0.5 \%$ & $-0.1 \%$ & $2.1 \%$ & $2.2 \%$ & $0.1 \%$ & $6.4 \%$ & $13.5 \%$ & $7.1 \%$ \\
\hline Samples & 5002 & 4629 & & 5473 & 4398 & & 8272 & 6703 & \\
\hline
\end{tabular}

Source: Calculated using CHIP1995, 2002 and 2007

Notes:

1) the gender wage gaps = female wage mean values/male wage mean values

2) the gender gaps of another variables $=$ female variable mean values-male variable mean values

$5 \%$, which indicates that the gender wage gap in these wage distribution intervals are obvious. However, as the wage level increases, the gender wage gap narrows accordingly, which shows that, except for groups with an extremely low-wage distribution, the 


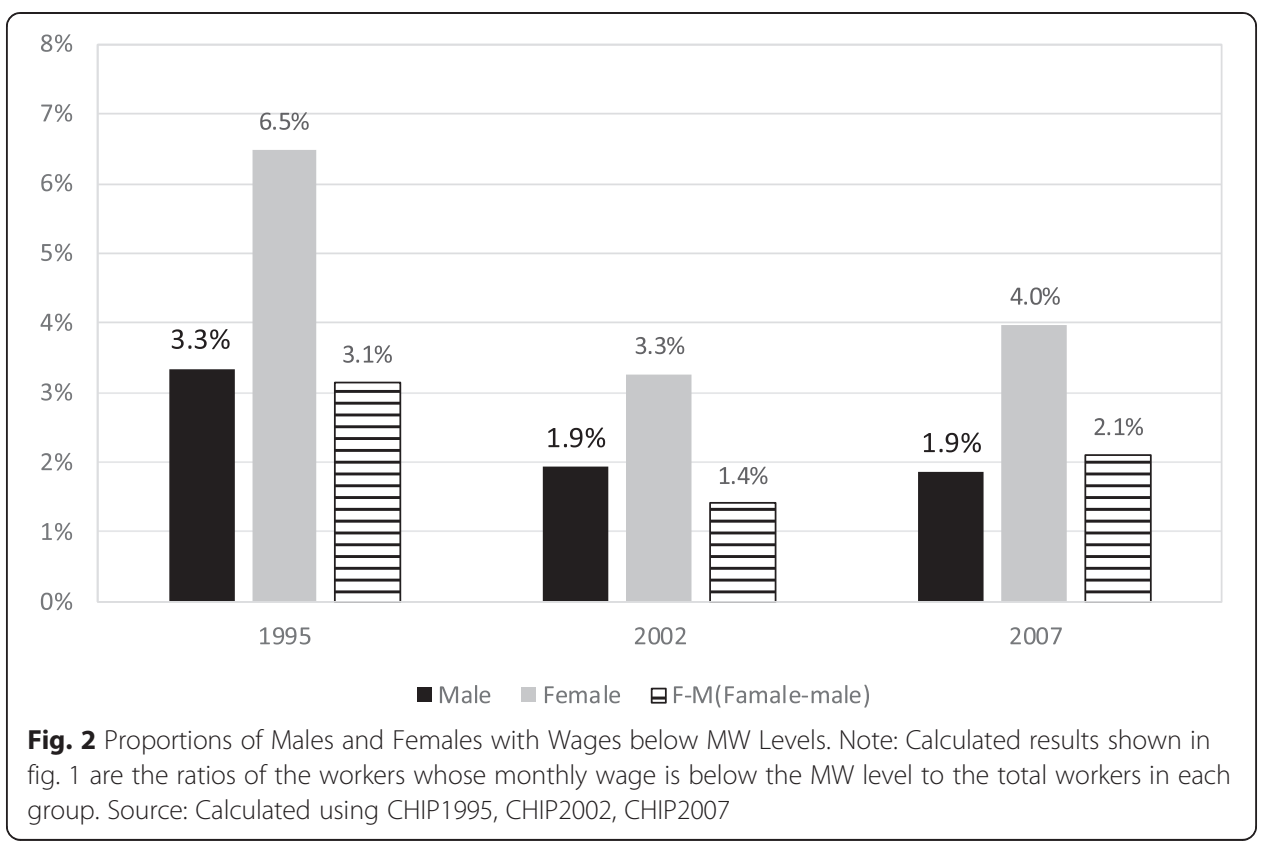

gender wage gaps in the low-wage distribution groups are greater than are those in middle- and high-wage distribution groups, i.e., there is the sticky floor phenomenon. (2) In high MW and middle MW regions in 1995, the gender wage gaps at the 1st and 3rd quantiles are not statistically significant. In 2007, however, an obvious gender wage gap at the 3rd quantile emerges. This may be because the proportion of females with wages lower than the MW level is greater than that of males in the early state of the implementation of the MW (see Fig. 1).

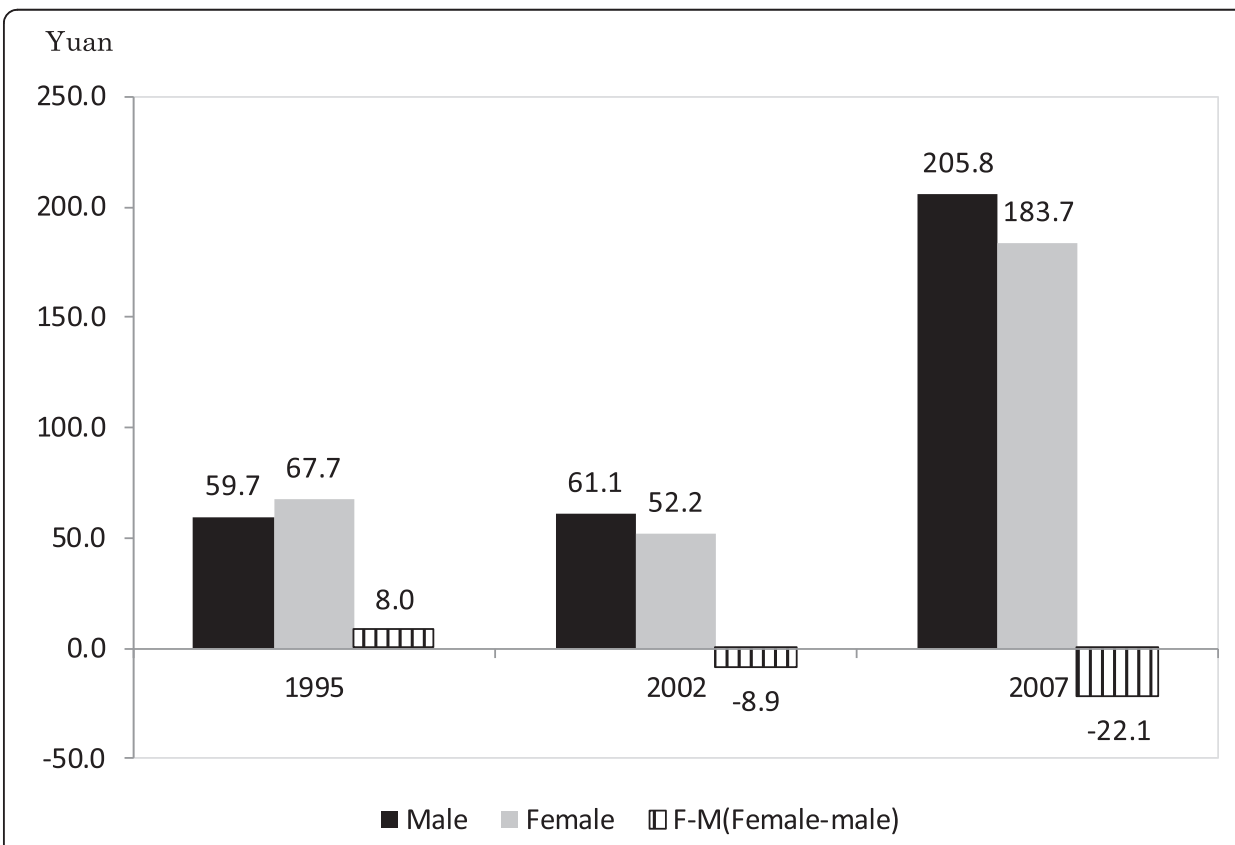

Fig. 3 Gender Gap and the Difference between Wage and MW Levels. Note: 1. Calculated results shown in fig. 2 are the gaps of wage level and the MW in each group. 2. Wages in three periods are adjusted by CPI. (based on 1995 national level). Source: Calculated using CHIP1995, CHIP2002, CHIP2007 
Table 3 Results of gender wage gaps in regions with different MW levels

\begin{tabular}{|c|c|c|c|c|c|c|c|c|}
\hline & \multicolumn{2}{|l|}{ Total } & \multicolumn{2}{|c|}{ High MW region } & \multicolumn{2}{|c|}{ Middle MW region } & \multicolumn{2}{|c|}{ Low MW region } \\
\hline & Coeff. & SE. & Coeff. & SE. & Coeff. & SE. & Coeff. & SE. \\
\hline \multicolumn{9}{|l|}{1995} \\
\hline Mean & $0.1141^{* * *}$ & 0.0116 & $0.1454^{* * *}$ & 0.0247 & $0.0762^{* * *}$ & 0.0201 & $0.1239^{* * *}$ & \\
\hline $1 \%$ & 0.3035 & 0.2239 & -0.0442 & 0.2594 & 0.0908 & 0.3016 & 0.4987 & 0.3284 \\
\hline $3 \%$ & $0.1867^{* * *}$ & 0.0411 & 0.1963 & 0.1409 & 0.2015 & 0.1283 & $0.2429^{* * *}$ & 0.0541 \\
\hline $6 \%$ & $0.1569^{* * *}$ & 0.0293 & $0.1986^{* * *}$ & 0.0579 & $0.1115^{* *}$ & 0.0474 & $0.1619^{* * *}$ & 0.0328 \\
\hline $10 \%$ & $0.1431^{* * *}$ & 0.0172 & $0.1747^{* * *}$ & 0.0439 & $0.1358^{* * *}$ & 0.0343 & $0.1303^{* * *}$ & 0.0278 \\
\hline $30 \%$ & $0.0885^{* * *}$ & 0.0110 & $0.1556^{* * *}$ & 0.0255 & $0.0540^{* *}$ & 0.0227 & $0.1041^{* * *}$ & 0.0156 \\
\hline $60 \%$ & $0.0708^{* * *}$ & 0.0113 & $0.1066^{* * *}$ & 0.0230 & $0.0634^{* * *}$ & 0.0176 & $0.0737^{* * *}$ & 0.0111 \\
\hline $90 \%$ & $0.0714^{* * *}$ & 0.0177 & $0.1238^{* * *}$ & 0.0365 & $0.0440^{*}$ & 0.0229 & $0.0692^{* * *}$ & 0.0194 \\
\hline \multicolumn{9}{|l|}{2002} \\
\hline Mean & $0.0955^{* * *}$ & 0.0126 & $0.0970^{* * *}$ & 0.0242 & $0.1249^{* * *}$ & 0.0185 & $0.0988^{* * *}$ & 0.0199 \\
\hline $1 \%$ & 0.0098 & 0.2381 & 0.2000 & 0.4666 & 0.1138 & 0.2534 & -0.0921 & 0.2274 \\
\hline $3 \%$ & $0.1279^{* * *}$ & 0.0452 & 0.1465 & 0.1037 & $0.1717^{* *}$ & 0.0707 & 0.0779 & 0.0691 \\
\hline $6 \%$ & $0.1269^{* * *}$ & 0.0265 & $0.1150^{* *}$ & 0.0504 & $0.1738^{* * *}$ & 0.0488 & $0.1062^{*}$ & 0.0624 \\
\hline $10 \%$ & $0.1120^{* * *}$ & 0.0200 & $0.1345^{* * *}$ & 0.0511 & $0.1302^{* * *}$ & 0.0322 & $0.1260^{* * *}$ & 0.0368 \\
\hline $30 \%$ & $0.0933^{* * *}$ & 0.0143 & $0.0857^{* * *}$ & 0.0288 & $0.0994^{* * *}$ & 0.0210 & $0.1000^{* * *}$ & 0.0276 \\
\hline $60 \%$ & $0.0925^{* * *}$ & 0.0137 & $0.1094^{* * *}$ & 0.0278 & $0.1129^{* * *}$ & 0.0173 & $0.1008^{* * *}$ & 0.0232 \\
\hline $90 \%$ & $0.0610^{* * *}$ & 0.0220 & $0.0736^{* *}$ & 0.0366 & $0.0952^{* * *}$ & 0.0244 & $0.0583^{* *}$ & 0.0293 \\
\hline \multicolumn{9}{|l|}{2007} \\
\hline Mean & $0.2277^{* * *}$ & 0.0119 & 0.2022 & 0.0312 & 0.2612 & 0.0183 & 0.2071 & 0.0185 \\
\hline $1 \%$ & 0.2592 & 0.1646 & 0.1173 & 0.7390 & 0.2011 & 0.2572 & 0.3540 & 0.3595 \\
\hline $3 \%$ & $0.3451^{* * *}$ & 0.0429 & $0.1410^{* * *}$ & 0.1684 & $0.3656^{* * *}$ & 0.0791 & $0.3492^{* * *}$ & 0.0881 \\
\hline $6 \%$ & $0.3137^{* * *}$ & 0.0271 & $0.2604^{* * *}$ & 0.0723 & $0.3285^{* * *}$ & 0.0365 & $0.3194^{* * *}$ & 0.0558 \\
\hline $10 \%$ & $0.2803^{* * *}$ & 0.0218 & $0.1769^{* * *}$ & 0.0527 & $0.3172^{* * *}$ & 0.0299 & $0.2871^{* * *}$ & 0.0347 \\
\hline $30 \%$ & $0.2156^{* * *}$ & 0.0134 & $0.2241^{* * *}$ & 0.0297 & $0.2431^{* * *}$ & 0.0178 & $0.2141^{* * *}$ & 0.0276 \\
\hline $60 \%$ & $0.2181^{* * *}$ & 0.0145 & $0.2396^{* * *}$ & 0.0335 & $0.2383^{* * *}$ & 0.0195 & $0.1751^{* * *}$ & 0.0186 \\
\hline $90 \%$ & $0.2319^{* * *}$ & 0.0190 & $0.1961^{* * *}$ & 0.0438 & $0.2921^{* * *}$ & 0.0333 & $0.1442^{* * *}$ & 0.0275 \\
\hline
\end{tabular}

Note:

1. Coefficients of the male dummy are showed in Table 3 (The other varibles are education, experience years, han race and the married dummy)

2. OLS based on wage mean, the results of $1 \% \sim 90 \%$ wage distribution are estimated using quantile regression model 3. ${ }^{*}, * *, * * *$ statistically significant in $10 \%, 5 \%, 1 \%$ levels Source: Calculated using CHIP1995, CHIP2002, CHIP2007

\subsection{Impact of MW level on males and females' wage}

To compare the effects of MW level and Kaitz Index on males and females' wage, we made the estimation by Model 1 (MW level model) and Model 2 (Kaitz Index model). The analysis results were obtained with OLS and the quantile regression model. The simulation results are shown in Fig. 4.

Seen from the estimated results of average value, if the MW level rises by 1 yuan, the increase of males and females' average wages are 3.2 yuan and 2.7 yuan, respectively, showing that the rise in the MW level has a slightly greater effect on males' average wage than on females' average wage. Seen from the estimated results of the wage quantile, only in the extreme low-wage distribution (e.g., 1st and 3rd quantile groups) does the rise in the MW standard have a slightly greater effect on females' average wages 


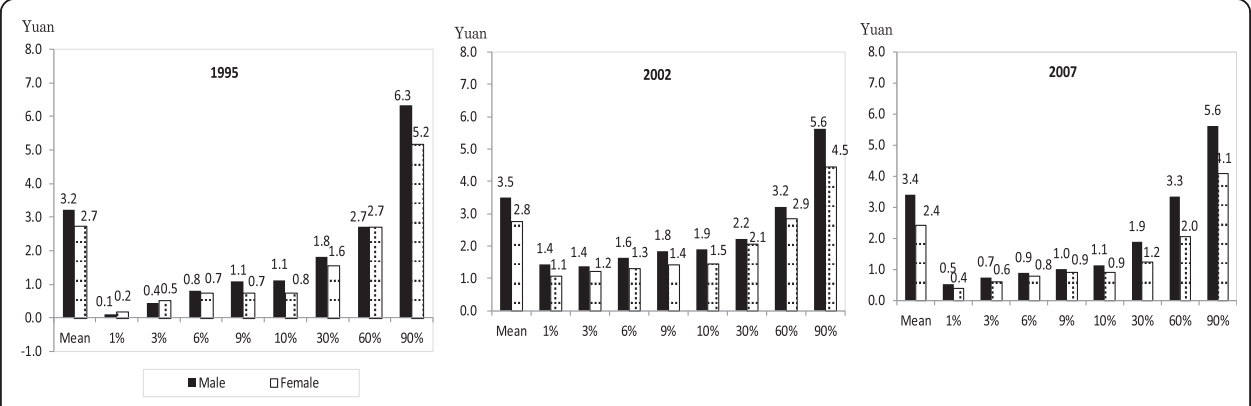

Fig. 4 Impact of MW Level on Males and Females' Wages. Note: 1. These are the simulation results showing wage rise level if the MW rise 100 Yuan. 2. OLS based on mean, the results of 1 percentile $~ 90$ percentile are estimated using quantile regression model. Source: Calculated using CHIP1995, CHIP2002, CHIP2007.

than on males' average wages. However, the opposite is the case in groups of other wage quantiles (e.g., the groups at middle/high wage levels); particularly in the highwage group (e.g., the group in the 90th quantile wage), the rise in the MW level has greater effect on males' wages.

\subsection{Decomposition results of gender wage gaps}

The results in Fig. 4 above show that the effect of the MW level on male and female wage levels differ from one another. To understand further the impact of the MW level on gender wage gap, we conducted the decomposition analysis for the gender wage gap by using the Oaxaca-Ransom decomposition model. Considering that the Kaitz Index may affect the gender wage gap, we also provide the decomposition result based on Kaitz Index. See the decomposition result in Table 4.

Above all, seen from the overall decomposition result, the effect of a difference in endowment return on gender wage gap is greater than that of endowment differentials. For example, in 1995, the difference in endowment return is $57.0 \%$ and the endowment difference is $43.0 \%$; in 2007 , the former is $36.5 \%$ and the latter is 63.5\%. The analysis result based on Kaitz Index also shows that, in both 1995 and 2007, the differences in endowment return are greater than endowment differentials. In 1995, the former is $56.3 \%$ and the latter is $43.7 \%$; in 2007 , the former is $60.5 \%$ and the latter is $39.5 \%$. Both composition results indicate that, from 1995 to 2007, the effect of differences in endowment return has increased. The increase in impact of differences in endowment return on gender wage gap shall be brought to the forefront because one of its causes lies in the increase in terms of effect of gender discrimination.

Now, we discuss the effect of MW level on gender wage gaps. In 1995, the endowment difference of the MW was $0.7 \%$, and the difference in endowment return of the MW was $-12.5 \%$, showing that the gender wage gap is caused by that proportion of males in the regions whose relatively high MW level is greater than those of females. The reason that the impact of the MW level on wage is greater for females than for males comes from the narrowing of the gender wage gap. Compared with the situation in 1995, the status is reversed in 2002. In 2002, the endowment difference of the MW level is $-3.0 \%$, and its difference in endowment return is $8.7 \%$. These numbers show that the reason that the proportion of workers in the regions with relatively high MW level is greater for females than for males is the narrowing of the gender wage gap, and 
Table 4 Decomposition results of the gender wage gaps

\begin{tabular}{|c|c|c|c|c|c|c|c|c|}
\hline & \multicolumn{4}{|c|}{ Decomposition (1)-The MW model } & \multicolumn{4}{|c|}{ Decomposition (2)-Kaitz Index model } \\
\hline & \multirow{2}{*}{$\begin{array}{l}\text { Endowment } \\
\text { differences }\end{array}$} & \multicolumn{3}{|l|}{ Return gaps } & \multirow{2}{*}{$\begin{array}{l}\text { Endowment } \\
\text { differences }\end{array}$} & \multicolumn{3}{|c|}{ Return gaps } \\
\hline & & Female loss (a) & Male gain (b) & Total $(a+b)$ & & Female loss (a) & Male gain (b) & Total $(a+b)$ \\
\hline \multicolumn{9}{|l|}{1995} \\
\hline $100 \%$ Decomposition results of each factor & $43.0 \%$ & $29.9 \%$ & $27.1 \%$ & $57.0 \%$ & $43.7 \%$ & $29.5 \%$ & $26.8 \%$ & $56.3 \%$ \\
\hline The MW & $0.7 \%$ & $-5.4 \%$ & $-7.1 \%$ & $-12.5 \%$ & & & & \\
\hline Kaitz Index & & & & & $-1.3 \%$ & $45.9 \%$ & $40.7 \%$ & $86.6 \%$ \\
\hline Education & $13.1 \%$ & $-3.0 \%$ & $-0.1 \%$ & $-3.1 \%$ & $14.7 \%$ & $-0.6 \%$ & $1.3 \%$ & $0.7 \%$ \\
\hline Experience years & $8.5 \%$ & $-125.2 \%$ & $-79.5 \%$ & $-204.7 \%$ & $9.0 \%$ & $-131.0 \%$ & $-86.6 \%$ & $-217.6 \%$ \\
\hline Race & $0.0 \%$ & $-16.9 \%$ & $-12.4 \%$ & $-29.3 \%$ & $0.0 \%$ & $-17.3 \%$ & $-13.3 \%$ & $-30.6 \%$ \\
\hline Married & $-0.4 \%$ & $39.3 \%$ & $43.1 \%$ & $82.4 \%$ & $-0.3 \%$ & $44.0 \%$ & $47.1 \%$ & $91.1 \%$ \\
\hline Ownership & $9.2 \%$ & $-2.0 \%$ & $1.9 \%$ & $-0.1 \%$ & $10.2 \%$ & $-2.1 \%$ & $1.8 \%$ & $-0.3 \%$ \\
\hline Occupation & $9.3 \%$ & $11.0 \%$ & $6.9 \%$ & $17.9 \%$ & $9.0 \%$ & $7.2 \%$ & $4.3 \%$ & $11.5 \%$ \\
\hline Industry & $2.6 \%$ & $-3.8 \%$ & $1.0 \%$ & $-2.8 \%$ & $2.4 \%$ & $-5.1 \%$ & $0.0 \%$ & $-5.1 \%$ \\
\hline Constant term & $0.0 \%$ & $135.8 \%$ & $73.3 \%$ & $209.1 \%$ & $0.0 \%$ & $88.5 \%$ & $31.5 \%$ & $120.0 \%$ \\
\hline \multicolumn{9}{|l|}{2002} \\
\hline 100\% Decomposition results of each factor & $48.8 \%$ & $28.6 \%$ & $22.6 \%$ & $51.2 \%$ & $52.9 \%$ & $26.2 \%$ & $20.9 \%$ & $47.1 \%$ \\
\hline The MW & $-3.0 \%$ & $2.4 \%$ & $6.3 \%$ & $8.7 \%$ & & & & \\
\hline Kaitz Index & & & & & $-1.8 \%$ & $18.3 \%$ & $5.7 \%$ & $24.0 \%$ \\
\hline Education & $6.3 \%$ & $2.1 \%$ & $-1.2 \%$ & $0.9 \%$ & $7.0 \%$ & $2.4 \%$ & $-0.2 \%$ & $2.2 \%$ \\
\hline Experience years & $15.6 \%$ & $-13.9 \%$ & $-4.8 \%$ & $-18.7 \%$ & $20.8 \%$ & $-20.0 \%$ & $-14.0 \%$ & $-34.0 \%$ \\
\hline Race & $0.0 \%$ & $23.2 \%$ & $20.8 \%$ & $44.0 \%$ & $0.0 \%$ & $25.9 \%$ & $21.3 \%$ & $47.2 \%$ \\
\hline Married & $1.3 \%$ & $20.4 \%$ & $27.6 \%$ & $48.0 \%$ & $0.5 \%$ & $19.0 \%$ & $27.6 \%$ & $46.6 \%$ \\
\hline Ownership & $6.6 \%$ & $-1.3 \%$ & $-0.4 \%$ & $-1.7 \%$ & $6.2 \%$ & $-1.7 \%$ & $-0.6 \%$ & $-2.3 \%$ \\
\hline Occupation & $17.9 \%$ & $6.8 \%$ & $-1.8 \%$ & $5.0 \%$ & $14.4 \%$ & $6.9 \%$ & $0.2 \%$ & $7.1 \%$ \\
\hline
\end{tabular}


Table 4 Decomposition results of the gender wage gaps (Continued)

\begin{tabular}{|c|c|c|c|c|c|c|c|c|}
\hline Industry & $4.1 \%$ & $6.9 \%$ & $1.1 \%$ & $8.0 \%$ & $5.8 \%$ & $5.0 \%$ & $-0.6 \%$ & $4.4 \%$ \\
\hline Constant term & $0.0 \%$ & $-18.1 \%$ & $-25.0 \%$ & $-43.1 \%$ & $0.0 \%$ & $-29.6 \%$ & $-18.5 \%$ & $-48.1 \%$ \\
\hline \multicolumn{9}{|l|}{2007} \\
\hline 100\% Decomposition results of each factor & $36.5 \%$ & $35.2 \%$ & $28.3 \%$ & $63.5 \%$ & $39.5 \%$ & $33.4 \%$ & $27.1 \%$ & $60.5 \%$ \\
\hline The MW & $1.2 \%$ & $1.7 \%$ & $6.4 \%$ & $8.1 \%$ & & & & \\
\hline Kaitz Index & & & & & $-0.5 \%$ & $-12.5 \%$ & $-4.3 \%$ & $-16.8 \%$ \\
\hline Education & $3.3 \%$ & $2.7 \%$ & $-6.0 \%$ & $-3.3 \%$ & $3.6 \%$ & $2.7 \%$ & $-5.0 \%$ & $-2.3 \%$ \\
\hline Experience years & $4.1 \%$ & $-21.1 \%$ & $-0.9 \%$ & $-22.0 \%$ & $7.4 \%$ & $-13.8 \%$ & $7.9 \%$ & $-5.9 \%$ \\
\hline Race & $0.2 \%$ & $-2.4 \%$ & $-4.7 \%$ & $-7.1 \%$ & $0.1 \%$ & $-4.3 \%$ & $-6.0 \%$ & $-10.3 \%$ \\
\hline Married & $0.8 \%$ & $23.0 \%$ & $24.7 \%$ & $47.7 \%$ & $0.5 \%$ & $18.1 \%$ & $19.4 \%$ & $37.5 \%$ \\
\hline Ownership & $14.3 \%$ & $-6.7 \%$ & $0.4 \%$ & $-6.3 \%$ & $14.1 \%$ & $-7.5 \%$ & $-0.5 \%$ & $-8.0 \%$ \\
\hline Occupation & $4.4 \%$ & $4.0 \%$ & $-3.5 \%$ & $0.5 \%$ & $4.8 \%$ & $5.3 \%$ & $-1.9 \%$ & $3.4 \%$ \\
\hline Industry & $8.2 \%$ & $-2.2 \%$ & $1.5 \%$ & $-0.7 \%$ & $9.5 \%$ & $-5.1 \%$ & $-1.3 \%$ & $-6.4 \%$ \\
\hline Constant term & $0.0 \%$ & $36.2 \%$ & $10.5 \%$ & $46.7 \%$ & $0.0 \%$ & $50.5 \%$ & $18.7 \%$ & $69.2 \%$ \\
\hline
\end{tabular}


the gender wage gap is caused by the MW level having relatively greater impact on wages for males than for females. In 2007, both the endowment difference and difference in endowment return of the MW level are positive values, i.e., 1.2\% (endowment difference) and $8.1 \%$ (difference in endowment return). These differences reveal that for both factors, the proportion of workers in the regions with relatively high MW level is greater for males than for females and that the MW level has greater impact on wages for males than for females, affecting the gender wage gap. The decomposition results of all three periods show that the gender difference in terms of the effect of the MW level on the wage (difference in endowment return) has a greater effect than the gender difference of the distribution in the regions with different MW levels (endowment difference).

Finally, we discuss the effect of the Kaitz Index on gender wage gap. In 1995, the endowment difference of the Kaitz Index is $-1.3 \%$ and the difference in endowment return of the Kaitz Index is $86.6 \%$. These results reveal that the reason that the proportion of workers in the regions with a relatively high Kaitz Index is greater for males than females is the narrowing gender wage gap, and the gender wage gap is caused by the Kaitz Index having a greater effect on wages for males than for females. In 2002, the direction of the Kaitz Index has an effect on gender wage gap similar to that in 1995; for example, the endowment difference of the Kaitz Index is $-1.8 \%$ and the difference in endowment return of the Kaitz Index is 24.0\%. Note that, compared with 1995, the reason that the Kaitz Index has a greater effect on wages for males than for females is that its effect decreased. In 2007, both the endowment difference and difference in endowment return of the Kaitz Index are negative values, i.e., $-0.5 \%$ (endowment difference) and $-16.8 \%$ (difference in endowment return). These changes have two causes: the proportion of females in the regions with relatively higher MW level is greater than that of males, and the Kaitz Index has greater effect on females' wage level, thus having an effect on narrowing the gender wage gap. The decomposition results of all three periods show that the gender difference in terms of the effect of the Kaitz Index on the wage (difference in endowment return) has a greater effect than does the gender difference of distribution in regions with different Kaitz Indexes (endowment difference).

\subsection{DID analysis results of gender wage gaps}

To further examine the effects of the MW implementation on gender wage gap, we also conducted DID analysis. See Table 5 (OLS) and Table 6(QR) for these results.

First, the effects of the MW on gender wage gap varied by period (Table 5). For example, the results in 1990-2007, 1991-2007 and 1992-2007 all showed that the MW implementation contributed to narrowing the gender wage gap. However, in other periods (such as 1990-1995 and 1990-2002), the effects of the MW on gender wage gap are statistically insignificant. These results indicate that the MW implementation contributes to narrowing the gender wage gap in the long term, but this effect is not obvious in the short term.

Second, the MW has a more noticeable effect on narrowing gender wage gap in low-wage and mid-wage groups (Table 6) in comparison with high-wage groups. However, the MW has a more significant effect on narrowing gender wage gap in the low-wage group, which is possibly because that increase of MW level has the 
Table 5 DID analysis results_-based on OLS estimations

\begin{tabular}{|c|c|c|c|c|c|c|}
\hline \multirow[b]{2}{*}{ The initial years: 1990} & \multicolumn{2}{|c|}{1990 vs. 1995} & \multicolumn{2}{|c|}{1990 vs. 2002} & \multicolumn{2}{|c|}{1990 vs. 2007} \\
\hline & Coeff. & SE. & Coeff. & SE. & Coeff. & SE. \\
\hline Male & $0.1327^{* * *}$ & 0.0123 & $0.1552^{* * *}$ & 0.0135 & $0.1404^{* * *}$ & 0.0086 \\
\hline year & 0.0062 & 0.0140 & $0.4767^{* * *}$ & 0.0194 & $0.7921^{* * *}$ & 0.0146 \\
\hline The treatment group & $-0.2598^{* * *}$ & 0.0233 & $-0.0947^{* * *}$ & 0.0183 & $-0.2110^{* * *}$ & 0.0198 \\
\hline Male*year & $0.0319^{*}$ & 0.0181 & $0.0420^{*}$ & 0.0253 & $0.1616^{* * *}$ & 0.0185 \\
\hline Male*The treatment group & $0.0649^{* *}$ & 0.0309 & $-0.1097^{* * *}$ & 0.0247 & $0.1361^{* * *}$ & 0.0254 \\
\hline year*The treatment & $-0.0817^{* *}$ & 0.0385 & -0.0144 & 0.0344 & $0.1712^{* * *}$ & 0.0409 \\
\hline \multirow[t]{2}{*}{ DIDterm } & -0.0077 & 0.0503 & 0.0572 & 0.0468 & $-0.1125^{* *}$ & 0.0508 \\
\hline & \multicolumn{2}{|c|}{1991 vs. 1995} & \multicolumn{2}{|c|}{1991 vs. 2002} & \multicolumn{2}{|c|}{1991 vs. 2007} \\
\hline The initial years: 1991 & Coeff. & SE. & Coeff. & SE. & Coeff. & SE. \\
\hline Male & $0.1249^{* * *}$ & 0.0133 & $0.1603^{* * *}$ & 0.0185 & $0.1194^{* * *}$ & 0.0112 \\
\hline year & 0.0207 & 0.0142 & $0.4845^{* * *}$ & 0.0214 & $0.8015^{* * *}$ & 0.0155 \\
\hline The treatment group & $-0.2753^{* * *}$ & 0.0230 & $-0.1201^{* * *}$ & 0.0223 & $-0.1263^{* * *}$ & 0.0206 \\
\hline Male*year & 0.0106 & 0.0191 & 0.0332 & 0.0284 & $0.1800^{* * *}$ & 0.0199 \\
\hline Male*The treatment group & 0.0252 & 0.0312 & $-0.1335^{* * *}$ & 0.0313 & $0.1060^{* * *}$ & 0.0306 \\
\hline year*The treatment & $-0.0819^{* *}$ & 0.0383 & 0.0107 & 0.0367 & $0.0866^{* *}$ & 0.0412 \\
\hline \multirow[t]{2}{*}{ DIDterm } & -0.0568 & 0.0504 & 0.0809 & 0.0506 & $-0.0803+$ & 0.0536 \\
\hline & \multicolumn{2}{|c|}{1992 vs. 1995} & \multicolumn{2}{|c|}{1992 vs. 2002} & \multicolumn{2}{|c|}{1992 vs. 2007} \\
\hline The initial years: 1992 & Coeff. & SE. & Coeff. & SE. & Coeff. & SE. \\
\hline Male & $0.1232^{* * *}$ & 0.0133 & $0.1429^{* * *}$ & 0.0187 & $0.1209^{* * *}$ & 0.0110 \\
\hline year & $-0.0525^{* * *}$ & 0.0141 & $0.4128^{* * *}$ & 0.0214 & $0.7325^{* * *}$ & 0.0153 \\
\hline The treatment group & $-0.2555^{* * *}$ & 0.0217 & $-0.1353^{* * *}$ & 0.0229 & $-0.1432^{* * *}$ & 0.0210 \\
\hline Male*year & 0.0150 & 0.0191 & $0.0529^{*}$ & 0.0285 & $0.1809^{* * *}$ & 0.0198 \\
\hline Male*The treatment group & $0.1262^{* * *}$ & 0.0303 & $-0.1127^{* * *}$ & 0.0325 & $0.1174^{* * *}$ & 0.0298 \\
\hline year*The treatment & $-0.1364^{* * *}$ & 0.0383 & 0.0256 & 0.0370 & $0.1028^{* *}$ & 0.0413 \\
\hline DIDterm & -0.0548 & 0.0496 & 0.0593 & 0.0513 & $-0.0922^{*}$ & 0.0531 \\
\hline
\end{tabular}

Note:

1. Estimations using Kaitz index in models. Treatment group: the region where the gender wage gap is lowest before the MW implementation, and the Kaitz index is higher after the MW implementation

2. The other varibles such as education, experience years, han race,married are also estimated

3. * **, *** statistically significant in $10 \%, 5 \%, 1 \%$ levels

Source: Calculated using CHIP1995,CHIP2002,CHIP2007

largest influence on wages of people in a low-wage group (i.e., at slightly higher or lower than MW level). Therefore, if there are more female than male workers at approximately the MW level, the increase of the MW level can narrow a gender wage gap. Figure 1 shows that, in three periods, the proportion of workers having wages lower than the MW level is greater for females than males. The related figures are 3.1 (1995), 1.4 (2002) and 2.1 (2007) percentage points. Why does the MW contribute to narrowing the gender wage gap of mid-wage groups? It may be due to the spread effect brought by a wage increase for low-wage groups (this effect is called "the spillover effect" of the MW); in other words, the wage of mid-wage groups will go up when that of low-wage groups goes up. The analysis results indicate that, in China's urban labor market, the increased MW level has influenced not only the lower-wage workers whose wage approaches the MW level but also wage levels to a significant extent. 
Table 6 DID analysis results-based on quantile regression estimations

\begin{tabular}{|c|c|c|c|c|c|c|c|}
\hline & $1 \%$ & $3 \%$ & $6 \%$ & $10 \%$ & $30 \%$ & $60 \%$ & $90 \%$ \\
\hline \multicolumn{8}{|l|}{ Estimation 1: 1990-2007 } \\
\hline \multirow[t]{2}{*}{ Male } & $0.4422^{* * *}$ & $0.2035^{* * *}$ & $0.2128^{* * *}$ & $0.1682^{* * *}$ & $0.1222^{* * *}$ & $0.1111^{* * *}$ & $0.1051^{* * *}$ \\
\hline & $(0.11)$ & $(0.05)$ & $(0.02)$ & $(0.02)$ & $(0.01)$ & $(0.01)$ & $(0.01)$ \\
\hline \multirow[t]{2}{*}{2002} & $0.5500^{* * *}$ & $0.4569^{* * *}$ & $0.5691 * * *$ & $0.5613^{* * *}$ & $0.6611^{* * *}$ & $0.8523^{* * *}$ & $1.0342^{* * *}$ \\
\hline & $(0.17)$ & $(0.05)$ & $(0.04)$ & $(0.03)$ & $(0.02)$ & $(0.01)$ & $(0.02)$ \\
\hline \multirow[t]{2}{*}{ The treatment group } & $-0.7978^{* * *}$ & 0.0713 & $-0.1811^{* * *}$ & $-0.1427^{* * *}$ & $-0.1868^{* * *}$ & $-0.2071^{* * *}$ & $-0.2191^{* * *}$ \\
\hline & $(0.23)$ & $(0.10)$ & $(0.05)$ & $(0.04)$ & $(0.02)$ & $(0.02)$ & $(0.02)$ \\
\hline \multirow[t]{2}{*}{ Male*2002 } & 0.0314 & $0.1528^{* *}$ & $0.1699 * * *$ & $0.2398^{* * *}$ & $0.2270^{* * * *}$ & $0.1502^{* * *}$ & $0.1279^{* * *}$ \\
\hline & $(0.22)$ & $(0.07)$ & $(0.05)$ & $(0.03)$ & $(0.02)$ & $(0.02)$ & 0.02 \\
\hline \multirow{2}{*}{$\begin{array}{l}\text { Male*The treatment } \\
\text { group }\end{array}$} & $0.9070^{* * *}$ & -0.0695 & $0.1269^{*}$ & $0.0933^{*}$ & $0.1007^{* * *}$ & $0.1074^{* * *}$ & $0.1466^{* * *}$ \\
\hline & $(0.32)$ & $(0.14)$ & $(0.07)$ & $(0.05)$ & $(0.03)$ & $(0.03)$ & $(0.03)$ \\
\hline \multirow{2}{*}{$\begin{array}{l}2002^{*} \text { The treatment } \\
\text { group }\end{array}$} & $1.2952^{* * *}$ & -0.0884 & 0.1387 & $0.1859^{* *}$ & $0.2392^{* * *}$ & $0.1778^{* * *}$ & 0.0311 \\
\hline & $(0.49)$ & $(0.16)$ & $(0.11)$ & $(0.08)$ & $(0.05)$ & $(0.04)$ & $(0.05)$ \\
\hline \multirow[t]{2}{*}{ DIDterm } & $-1.0092+$ & $0.3830^{*}$ & 0.0767 & -0.0594 & $-0.1357^{* *}$ & $-0.1329^{* * *}$ & $-0.1074^{*}$ \\
\hline & $(0.64)$ & $(0.21)$ & $(0.14)$ & $(0.10)$ & $(0.06)$ & $(0.05)$ & $(0.06)$ \\
\hline \multicolumn{8}{|l|}{ Estimation 2: 1991-2007 } \\
\hline \multirow[t]{2}{*}{ Male } & $0.3238^{* *}$ & $0.1477^{* * *}$ & $0.1267^{* * *}$ & $0.0947^{* * *}$ & $0.1058^{* * *}$ & $0.1084^{* * * *}$ & $0.1221^{* * *}$ \\
\hline & $(0.16)$ & $(0.04)$ & $(0.03)$ & $(0.02)$ & $(0.02)$ & $(0.01)$ & $(0.02)$ \\
\hline \multirow[t]{2}{*}{2007} & $0.3839^{* *}$ & $0.4934^{* * *}$ & $0.5300^{* * * *}$ & $0.5603^{* * * *}$ & $0.6992^{* * *}$ & $0.8726^{* * *}$ & $1.0636^{* * *}$ \\
\hline & $(0.19)$ & $(0.05)$ & $(0.04)$ & $(0.03)$ & $(0.02)$ & $(0.02)$ & $(0.02)$ \\
\hline \multirow[t]{2}{*}{ The treatment group } & 0.4178 & 0.0951 & 0.0212 & -0.0655 & $-0.1340^{* * *}$ & $-0.1794^{* * *}$ & $-0.1497^{* * *}$ \\
\hline & $(0.35)$ & $(0.09)$ & $(0.06)$ & $(0.05)$ & $(0.03)$ & $(0.03)$ & $(0.04)$ \\
\hline \multirow[t]{2}{*}{ Male*2007 } & 0.1083 & $0.1845^{* * *}$ & $0.2462^{* * *}$ & $0.3133^{* * *}$ & $0.2370^{* * *}$ & $0.1620^{* * *}$ & $0.0891^{* * *}$ \\
\hline & $(0.25)$ & $(0.06)$ & $(0.05)$ & $(0.03)$ & $(0.02)$ & $(0.02)$ & $(0.03)$ \\
\hline \multirow{2}{*}{$\begin{array}{l}\text { Male*The treatment } \\
\text { group }\end{array}$} & -0.2488 & -0.0211 & 0.0474 & 0.0868 & $0.0848^{*}$ & $0.1194^{* * *}$ & $0.1394^{* *}$ \\
\hline & $(0.47)$ & $(0.12)$ & $(0.09)$ & $(0.06)$ & $(0.05)$ & $(0.04)$ & $(0.06)$ \\
\hline \multirow{2}{*}{$\begin{array}{l}2007^{*} \text { The treatment } \\
\text { group }\end{array}$} & -0.0204 & -0.1441 & -0.0441 & 0.1129 & $0.1796^{* * *}$ & $0.1606^{* * *}$ & -0.0536 \\
\hline & $(0.56)$ & $(0.14)$ & $(0.10)$ & $(0.07)$ & $(0.06)$ & $(0.05)$ & $(0.07)$ \\
\hline \multirow[t]{2}{*}{ DIDterm } & 0.2135 & $0.3710^{* *}$ & 0.1540 & -0.0571 & -0.1155 & $-0.1542^{* *}$ & -0.0654 \\
\hline & $(0.74)$ & $(0.19)$ & $(0.14)$ & $(0.10)$ & $(0.07)$ & $(0.06)$ & $(0.09)$ \\
\hline \multicolumn{8}{|l|}{ Estimation 3: 1992-2007 } \\
\hline \multirow[t]{2}{*}{ Male } & 0.2417 & $0.2588^{* * *}$ & $0.1727^{* * *}$ & $0.1212^{* * *}$ & $0.1189^{* * *}$ & $0.1166^{* * *}$ & $0.1169^{* * *}$ \\
\hline & $(0.16)$ & $(0.04)$ & $(0.03)$ & $(0.02)$ & $(0.01)$ & $(0.01)$ & $(0.02)$ \\
\hline \multirow[t]{2}{*}{2007} & 0.2376 & $0.5811^{* * *}$ & $0.4781^{* * *}$ & $0.4874^{* * *}$ & $0.6212^{* * *}$ & $0.8106^{* * *}$ & $1.0110^{* * *}$ \\
\hline & $(0.19)$ & $(0.05)$ & $(0.04)$ & $(0.02)$ & $(0.02)$ & $(0.01)$ & $(0.02)$ \\
\hline \multirow[t]{2}{*}{ The treatment group } & 0.2146 & $-0.3440 * * *$ & -0.0263 & $-0.0801^{*}$ & $-0.1489^{* * *}$ & $-0.1802^{* * *}$ & $-0.1702^{* * *}$ \\
\hline & $(0.34)$ & $(0.08)$ & $(0.06)$ & $(0.04)$ & $(0.03)$ & $(0.03)$ & $(0.04)$ \\
\hline \multirow[t]{2}{*}{ Male*2007 } & 0.2195 & 0.0831 & $0.2087^{* * *}$ & $0.2808^{* * *}$ & $0.2264^{* * *}$ & $0.1512^{* * *}$ & $0.1060^{* * *}$ \\
\hline & $(0.24)$ & $(0.07)$ & $(0.05)$ & $(0.03)$ & $(0.02)$ & $(0.02)$ & $(0.03)$ \\
\hline \multirow{2}{*}{$\begin{array}{l}\text { Male*The treatment } \\
\text { group }\end{array}$} & -0.0364 & $0.3459^{* * *}$ & 0.0672 & 0.0678 & $0.0782^{*}$ & $0.1153^{* * *}$ & $0.1342^{* * *}$ \\
\hline & $(0.45)$ & $(0.11)$ & $(0.09)$ & $(0.06)$ & $(0.04)$ & $(0.04)$ & $(0.05)$ \\
\hline
\end{tabular}


Table 6 DID analysis results-based on quantile regression estimations (Continued)

\begin{tabular}{llllllll}
\hline 2007*The treatment & 0.1879 & $0.2933^{*}$ & -0.0157 & $0.1319^{*}$ & $0.2049^{* * *}$ & $0.1544^{* * *}$ & -0.0319 \\
group & $(0.55)$ & $(0.16)$ & $(0.10)$ & $(0.07)$ & $(0.05)$ & $(0.04)$ & $(0.06)$ \\
\multirow{2}{*}{ DIDterm } & 0.0100 & -0.0103 & 0.1452 & -0.0351 & $-0.1187^{*}$ & $-0.1429^{* *}$ & -0.0684 \\
& $(0.72)$ & $(0.21)$ & $(0.14)$ & $(0.09)$ & $(0.07)$ & $(0.06)$ & $(0.08)$ \\
\hline
\end{tabular}

Note:

I. The other variables such as education, experience years, han race,married are also estimated

2. SE values are showed in ( )

3. $+, *{ }^{* *}, * * *$ statistically significant in $15 \%, 10 \%, 5 \%, 1 \%$ levels

Source: Calculated using CHIP1995, CHIP2002, CHIP2007

\section{Conclusions}

In urban China, the gender wage gap was small during the period of planned economy; however, during the economy transition period, particularly after the 1990s, when SOEs were further reformed, the gender wage gap gradually increased. Conversely, the Chinese government has been officially implementing the MW system since 1993. The implementation of the MW policy contributes to increasing incomes of low-wage groups. Therefore, if the proportion of workers with wages lower than the MW level is greater for females than for males, the MW may narrow gender wage gap. This paper provides evidence on whether the MW has had an effect on gender wage gaps in urban China using CHIP1995, 2002 and 2007. Several major conclusions emerge.

First, by the descriptive statistical analysis, we had the following two findings. (1) In 1995, 2002 and 2007, the proportion of workers with wages lower than the MW level was greater for females than for males. (2) The gaps between wages and the MW level for males and females are different during three periods. In addition, the local MW levels in different regions influence males and females' wages differently.

Second, the gender wage gap is largest in regions with high MW levels, and smallest in regions with middle MW levels. Although the gender wage gap is not obvious at the extremely low-wage distribution (e.g., in the 1st quantile), in wage distributions in which quantile is higher than 6th, the gender wage gap tends to narrow with increasing wage levels, showing that there is a sticky floor phenomenon.

Furthermore, the decomposition results using the Oaxaca-Ransom model show that gender differences in returns on endowments in the MW levels and Kaitz Index have a greater influence on gender wage gap, in comparison with gender differences in endowments.

Finally, the results obtained by DID analysis model show that, in the long term, implementation of a MW system contributes to narrowing gender wage gap and that such an effect in a low-wage group is more significant than that in a high wage group. However, that effect is not obvious in the short term.

Although according to these empirical analysis, we can conclude that the MW implementation contributes to narrowing gender wage gap in the long term, there are three points worthy of attention. First, the analysis results show that MW started to contribute to narrowing the gender wage gap after the MW system had been implemented for 15-17 years $(1990,1991,1992-2007)$ and that the gender wage gap had hardly been influenced during a shorter period of implementation of this system. Why does the long-term effect differ from the short-term effect? It is necessary to extend the analysis in the future. This may be because we could only use the quasi-DID model instead of 
the real DID analysis model. Second, the MW system has a greater influence on gender wage gap at an extremely low-wage distribution, which may be related to a greater proportion of females at the low-wage distribution. To further analyze the causes of gender wage gap at the low-wage distribution is a promising area of issues for discussion, such as an in-depth investigation of females' poverty.

Third, although this paper only discusses the MW effect on gender wage gaps, there may be gender gap effects of unemployment and informality (Hunt 2002; Muravyev and Oshchepkov 2013). ${ }^{17}$ There are many factors influencing female labor participation such as household structure, macro-economic environment, firm recruitment, and employment system, so detailed empirical studies on this issue should be done in the future.

\section{Endnotes}

${ }^{1}$ For other empirical studies on the gender wage gap that don't focus on the MW effect, please see Gustafsson and Li (2000), Li and Ma (2006), Li and Song (2013), Ma (2008 and 2010).

${ }^{2}$ Regarding the debate on the MW employment effect in the 1980s, it is indicated that there is a negative significant but modest $-1 \%$ to $-3 \%$ employment effect (Brown, et al., 1982). After the 1990s, using cross-section data, Meyer and Wise (1983a, b) Neumark and Wascher (1992, 2000 and 2004); Deere et al. (1995); Currie and Fallick (1996) and Burkhauser et al. (2000) also found results consistent with the standard model prediction of a negative employment effect. On the other hand, using panel data to conduct quasi-natural experiment studies, Card (1992a,1992b); Katz and Krueger (1992); Card and Krueger (1995) pointed out that there are no unemployment effects. Similarly, there is no consensus on the effect of MW on employment.

${ }^{3}$ We apply Chinese National Minimum Wage Databases to classify the regions by the MWLevel; the regions are shown in Table 1.

${ }^{4}$ Another approach to investigating regional differences in the gender wage gap is to use the cross term of males and regions. However, such an approach compares based on the assumption that there is the same endowment of human capital in each region, which allows for variables with assumptions but is not very realistic. We therefore relax the limiting conditions to estimate by region groups. Anyone who is interested in the results of using cross term may contact the author directly.

${ }^{5}$ The Oaxaca-Blinder composition method can be expressed with the following two equations. Please note that the coefficient estimates and average of variables used in Eqs. (10) and (11) are different.

$$
\begin{aligned}
& \ln \bar{W}_{m}-\ln \bar{W}_{f}=\beta_{m}\left(\bar{X}_{m}-\bar{X}_{f}\right)+\left(\beta_{m}-\beta_{f}\right) \bar{X}_{f} \\
& \ln \bar{W}_{m}-\ln \bar{W}_{f}=\beta_{f}\left(\bar{X}_{f}-\bar{X}_{m}\right)+\left(\beta_{f}-\beta_{m}\right) \bar{X}_{m}
\end{aligned}
$$

${ }^{6}$ Strictly speaking, the decomposition value here does not represent discrimination as a whole because it also contains a part of the gap resulting from some interpreted variables that cannot be observed, for example, working attitude and abilities. 
${ }^{7}$ The Kaitz index is defined as the ratio of the MW to the average wage of the working population.

${ }^{8}$ Please note that we can use only the quasi-DID model rather than the real DID model. The main reason is that the Chinese government published the Minimum Wage Regulations for Enterprises in 1993, and the MW policy was carried out in all regions (provinces) covered by the CHIP survey. In other words, we cannot find the real control group (the province in which the MW is not implemented during two compared periods). Therefore, we applied this alternative method.

${ }^{9}$ Meyer (1995, pp.157-158) noted that to improve the robustness of the quasi-natural experiment model, the use of multiple treatment groups and multiple comparison groups is the development direction of future quasi-natural experiments. Based on that statement, this paper has made full use of the characteristics of CHIP data and selected multiple treatment groups and control groups when applying the DID method.

${ }^{10}$ Based on the definition proposed in this paper, we use Hernan (1990 vs. 1995), Hubei (1990 vs. 2002), Shanxi (1990 vs. 2007), Shanxi (1991 vs. 1995), Hubei (1991 vs. 1992), Shanxi (1991 vs. 2007), Shanxi (1992 vs. 1995), Hubei (1992 vs. 2002), Shanxi (1992 vs. 2007) as treatment groups.

${ }^{11}$ There may be representative error when make the master sample by consolidating the data in each region. Therefore, the weight can be used for adjustment. However, it is not applied in this paper, first, because CHIP is applied by the NBS according to a national survey sample. It is a stratified multiple stage sample in which the master sample consolidating error arising from the difference in sample number in regions can be forecast to be very small. Second, according to the calculation of Li and Song (2013), the population census data in 2000 and 1\% population census data against CHIP2002 and CHIP2007 are used as the weight. The adjusted results are the same as the results without being adjusted. Moreover, no relevant data against CHIP1995 can be used to correct it. For more details regarding this point, please see Li and Song (2013, note 1).

${ }^{12}$ According to the MW Article published in 1993, the main content of the MW consist of total earnings from work (except the overtime hours subsidy), any risk job subsidy and social security subsidy. We cannot distinguish the detail subsidy items from CHIP data. We also made an analysis using the basic wage. The results are similar to the results using the total wage. Therefore, we show the results using total wage in this paper. The earnings data does not include unofficial payments, and if such payments are more likely to be made to men, the gender wage gap will be underestimated.

${ }^{13} \mathrm{We}$ calculated the total values of the material objects and added them to wage accounts.

${ }^{14}$ There are two reasons for using the logarithm of monthly wage as the explained variable.First, there is only monthly wage information in the CHIP 2007; therefore, we calculated monthly wage using CHIP1995 and CHIP2002. Second, the MW standard for a regular worker in each region is defined based on a monthly wage. The data of the urban worker in the CHIP we use is dominated by regular worker data, so we perform the analysis by taking the regular worker as the object according to the MW standard based on monthly wage. Therefore, we use the corresponding logarithm of the monthly wage as the explained variable in the wage function.

${ }^{15}$ In China, college courses are for three years whereas university courses are over four years. 
${ }^{16}$ Experience years $=$ age - years of education

${ }^{17}$ Hunt (2002) shows that with a fall in the gender wage gaps, the unemployment of low-skilled women increased in Germany. Muravyev and Oshchepkov (2013) further indicates the effects of MW on the informality and unemployment in Russian regions.

\section{Competing interests}

The IZA Journal of Labor \& Development is committed to the IZA Guiding Principles of Research Integrity. The authors declare that they have observed these principles.

\section{Acknowledgments}

We are very grateful to Tony Fang and the participants in the Minimum Wage Policy in Developing Countries Workshop in Beijing October 2014 for their extremely helpful comments on October 18-19, 2014, at the Beijing Minimum Wage Conference and on January 6-8, 2015, at the CES annual joint meeting with ASSA and AEA, Boston. We would like to express our special thanks to the financial support from IDRC. We also would like to thank anonymous referees for very useful comments and helpful suggestions. All remaining errors are ours.

Responsible editor: Hartmut Lehmann

\section{Author details}

${ }^{1}$ Business and Economics School, Beijing Normal University, No.19 Xin Jie Kou Wai St., Beijing 100875, China. ${ }^{2}$ Institute of Economic Research, 2-1 Naka, Kunitachi-shi, Tokyo 186-8603, Japan.

Received: 19 March 2015 Accepted: 23 October 2015

Published online: 30 November 2015

\section{References}

Blinder A (1973) Wage discrimination: reduced form and structural estimates. J Hum Resour 8(4):436-455

Brown C, Curtis G, Andrew K (1982) The effect of the minimum wage on employment and unemployment. J Econ Lit 20(2):487-528

Burkhauser RV, Kenneth A, Wittenburg DC (2000) A reassessment of the new economics of the minimum wage. J Labor Econ 18(4):653-681

Card D (1992a) Using regional variation in wages to measure the effects of the federal minimum wage. Ind Labor Relat Rev 46(1):22-37

Card D (1992b) Do minimum wages reduce employment? A case study of California, 1987-89. Ind Labor Relat Rev 46(1):38-54

Card D, Krueger A (1995) Myth and measurement: the new economics of the minimum wage. Princeton University Press, Princeton, NJ

Cotton J (1988) On the decomposition of wage differentials. Rev Econ Stat 70(2):236-243

Currie J, Fallick B (1996) The minimum wage and the employment of youth: evidence from the NLSY. J Hum Resour 31(2):404-428

Deere D, Murphy K, Welch F (1995) Employment and minimum wage hike. Am Econ Rev Pap Proc 85:232-237

DiNardo J, Fortin NM, Lemieux T (1996) Labor Market Institutions and the Distribution of Wages, 1973-1992: A Semiparametric Approach, Econometrica 64(5):1001-1044

Gustafsson B, Li S (2000) Economic transformation and the gender earnings gap in Urban China. J Popul Econ 13(2):305-329

Hunt J (2002) The transition in East Germany: when is a ten-point fall in the gender wage gap bad news? J Labor Econ 20(1):148-169

Katz LF, Krueger AB (1992) the effect of the minimum wage on the fast food industry. Ind Labor Relat Rev 46(1):6-21 Koenker RW, Bassett GJ (1978) Regression Quantile, Econometrica, 46(1):33-50.

Li S, Gustafsson B (2008) Unemployment, earlier retirement, and changes in the gender income gap in Urban China,1995-2002. In: Gustafsson B, Li S, Sicular T (eds) Income inequality and public policy in China. Cambridge University Press, Cambridge

Li S, Ma X (2006) The gender wage gaps and gender occupational segmentation in Urban China. Chin Popul Sci 2006(5):1-14 (in Chinese)

Li S, Song J (2013) The Change of Gender Wage Gaps in Urban China. In Li S, Sato H, Sicular T (2013). The Analysis of the Changes of Income Distribution in China (ZHOUGUO SHOURU CHAJU BIANGONG FENXI): Chinese Income Distribution Studies IV The People's Press, Beijing: 423-457. (in Chinese)

Ma X (2008) Gender gaps in wages of re-employment workers and employment restructuring in China. Jpn J Labor Stud 571:104-119 (in Japanese)

Ma X (2010) The comparison of gender wage differentials by wage distribution in Japan and China. Mita Bus Rev 52(6):69-87 (in Japanese)

Meyer BD (1995) Natural and quasi-experiments in economics. J Bus Econ Stat 13(2):151-161

Meyer RH, Wise DA (1983a) The effect of the minimum wage on the employment and earnings of youth. J Labor Econ $1: 66-100$

Meyer RH, Wise DA (1983b) Discontinuous distributions and missing persons: the minimum wage and unemployment youth. Econometrica 51(6):1677-1698

Muravyev A, Oshchepkov AY (2013) Minimum wages, unemployment and informality: evidence form panel data on Russian Regions, IZA Discussion Paper No.7878

Neumark D (1988) Employer's discriminatory behavior and the estimation of wage discrimination. J Hum Resour 23(3):279-295 
Neumark D, Wascher W (1992) Employment effects of minimum and subminimum wages: panel data on state minimum wage laws. Ind Labor Relat Rev 46(1):55-81

Neumark D, Wascher W (2000) The effect of New Jersey. Minimum wage increase on fast-food employment: a reevaluation using payroll records. Am Econ Rev 90(5):1362-1396

Neumark D, Wascher W (2004) Minimum wages, labor market institutions, and youth employment: a cross-national analysis. Ind Labor Relat Rev 57(2):223-248

Neumark D, Wascher W (2006) Minimum wages and employment: a review of evidence from the new minimum wage, Research Working Paper

Oaxaca RL (1973) Male-female wage differentials in urban labor markets. Int Econ Rev 14(3):693-709

Oaxaca RL, Ransom MR (1994) On discrimination and the decomposition of wage differentials. J Econ 61(1):5-21

Robinson H (2002) Wrong side of the track? The impact of the minimum wage on gender pay gaps in Britain. Oxf Bull Econ Stat 64(5):417-448

Robinson $\mathrm{H}$ (2005) Regional evidence on the effect of the national minimum wage on the gender pay gap. Reg Stud 39(7):855-875

Shannon MT (1996) Minimum wages and the gender wage gap. Appl Econ 28(12):1567-1576

Submit your manuscript to a SpringerOpen ${ }^{\circ}$ journal and benefit from:

- Convenient online submission

- Rigorous peer review

- Immediate publication on acceptance

- Open access: articles freely available online

- High visibility within the field

- Retaining the copyright to your article

Submit your next manuscript at $>$ springeropen.com 